\title{
Study of risk factors in patients hospitalized for psychotic disorders in the dalal xel mental health center in Fatick (Senegal)
}

\begin{abstract}
Introduction: Psychiatric disorders are characterized by the complexity of their psychodynamic mechanisms and the inadequacy of therapeutic means. This work aims to study the risk factors of psychotic pathologies in Dalal Xel hospital of Fatick.

Materials and Methods: This is a cross-sectional, retrospective, study carried out between 02 June and 21 July 2014 in the Dalal Xel mental health center in Fatick. All patients hospitalized in this facility were included between November 2003 and April 2014 and their medical records were retrieved. Simple logistic regression was used to analyze the data.

Results: Of the 7274 patient records collected, the average age was 34.3years $( \pm 20.32)$, men were the majority at $61.2 \%$ and $57.6 \%$ were from rural areas. Serer represented $39.6 \%$ of cases. The $34.9 \%$ were out of school. Psychotic forms were mostly represented $(56.8 \%)$. The main factors related to psychosis after adjustment are age between 16 and 40years $(\mathrm{OR}=6,5[5,0-8,5])$, marriage $(\mathrm{OR}=0.7 \mathrm{IC}=[0.6-0.8])$, the death of the father $(\mathrm{OR}=1.3 \mathrm{IC}=[1.1-1.5])$, the death of the mother $(\mathrm{OR}=1.4 \mathrm{IC}=[1.1$ $-1.9])$.

Conclusion: Psychotic disorders are influenced by the socio-family experience of the individual. Marriage, orphan status and family support have been identified as risk factors in psychosis, hence the importance of involving the family in patient follow-up and in the development of mental health policies.
\end{abstract}

Keywords: risk factors, psychiatric pathologies, dalal xel, Fatick, senegal
Volume 6 Issue I - 2017

\author{
Seck I,' Tine Jad,' DIOUF M,' Niang K,' SY \\ $\mathrm{A},{ }^{2} \mathrm{BA}$ EHM, ${ }^{2}$ Faye $\mathrm{FN},{ }^{3}$ Tal Dia $\mathrm{A}^{\prime}$ \\ 'Institute of Health and Development (ISED)/UCAD, Senegal \\ ${ }^{2}$ Hospital Fann, Senegal \\ ${ }^{3}$ Dalal Xel Mental Health Center, Senegal
}

\begin{abstract}
Correspondence: DIOUF M, Department of Epidemiology and Public Health, Institute of Health and Development (ISED)/ UCAD, Senegal, Tel 00221706578628
\end{abstract} Email dioufmass78@yahoo.fr

Received: January 12, 2017 | Published: June 12, 2017

\section{Introduction}

Psychotic pathologies have the particularity of being often chronic and costly. According to Charrier, the direct costs associated with schizophrenia range from US \$16billion in the United States to US \$204billion in the United Kingdom and \$79billion in Canada. ${ }^{1}$ Developing countries, particularly those in Africa, are no exception. Those who are already struggling with their inadequate health systems and on a small budget do not have the means to cope with the growing mental health problems. ${ }^{2}$ Since 1956, Senegal has set up psychiatric structures to provide a sanitary environment for the mentally ill with the creation of the neuropsychiatry department of the Fann hospital. In 1994, the first private non-profit psychiatric structure was created as the mental health center "Dalal Xel" in Thiès. Then in 2003, another health center "Dalal Xel" was opened in Fatick. This partnership between the Order of "Saint-Jean de Dieu" and the State of Senegal has increased the coverage and quality of mental health services. Dalal Xel's mental health care providers offer a range of preventive and curative services to the population. ${ }^{3}$ The aim of this study was to study the risk factors of psychotic pathologies hospitalized in Dalal Xel of Fatick to allow a better understanding of the psychopathological processes of these diseases.

\section{Method}

This was a cross-sectional that took place in Dalal Xel mental health center. The mental health center is located at the entrance of the town of Fatick on $150 \mathrm{~km}$ from Dakar and $65 \mathrm{~km}$ from Mbour. The
"Dalal Xel" system is under the guidance of the Consultative Council. Their activities of the psychiatric center are general psychiatric consultation, adult hospitalization and occupational therapies such as gardening, weaving and games of mind (card game, lady's play).

\section{Sampling and data collection}

This study was exhaustive, on the basis of the hospitalization register and patient records. It was included all patients who were recorded in the hospitalization records of the structure between November 2003 and April 2014. It was excluded those registries that did not have a diagnosis clearly identified by the psychiatrist. In each hospitalization unit, there is a register at the nurses' room and a file at the doctor's office. All the patient files, found in the hospitalization units of the structure and belonging to the study period, were collated in a seizure mask made on Microsoft Access 2007 by two seizure operators trained and taken care of by the structure. The analysis of the data was done with Epi-info 3.5.3 and with R 3.1.1 software. The qualitative variables have been described by their frequency and confidence interval at $95 \%$ and the quantitative variables described by their mean and standard deviation. Variables were cross-fertilized to meet the expectations of the determinants objectives. This was done using the tests of Khi2 or Student according to their applicability conditions with a significance threshold $(\mathrm{p}=0.05)$. The odds ratio, surrounded by its confidence interval, quantified the strength of the link. A multivariate analysis was performed with a simple logistic regression for the determination of factors related to psychosis, with an adjustment to the variables related to the individual, family 
and occupational characteristics while ensuring the conditions of applicability with a threshold of significance set at 5\%. Variables with $\mathrm{p}$ values less than 0.25 in bivariate analysis were used for modeling. ${ }^{4}$ The lrtest (likelihood ratio) and AIC allowed the choice of the last one with the step-by-step descending method. Finally, the Hosmer Lemeshow test made it possible to test the suitability of the final model. In the final model, the associations were measured by the odds ratio with their confidence intervals. ${ }^{5}$

\section{Ethical considerations}

This study was initiated as part of an evaluation of the activities of the Dalal Xel mental health center in collaboration with the head of the health center. The data is collected anonymously. No judgment of subjective, personified or group value that may taint the personality of the individuals and the institution will be published in this study. No remuneration or financial or material compensation was offered to the patients.

\section{Results}

\section{Clinical Features}

Between November 2003 and April 2014, there were 7274 patients who were hospitalized at the Dalal Xel psychiatric center in Fatick. By filing the records, it was found that $91.5 \%$ (or 6660 patients) of the cases had a diagnosis of discharge. Of these patients with a diagnosis, $72.8 \%$ (or 4848 cases) had psychiatric illnesses, 2.5\% (1766 cases) had neurological diseases as a cause of hospitalization, and the rest had general medicines such as gastric disturbances, infectious syndromes. In the psychiatric illness group, 77.6\% (or 3763 cases) had psychoses, $15 \%$ (or 728 cases) had mood disorders (depression, mania, bipolar disorder) and $7.4 \%$ (or 357 cases) were neurotic according to the psychiatric classification of the French school. In the psychotic group, using International Classification of Disease 10 version (ICD10), we found that $34.3 \%$ (or 1291 cases) had schizophrenic disorders, $32.1 \%$ (or 1207 cases) had acute delusional disorders, 15\% (566 cases) had mental disorders related to psychoactive substances. Chronic hallucinatory psychotic disorders and non-dissociative psychotic disorders accounted for 8.9\% (336 cases) and 6.9\% (225 cases) respectively. The mental disorders associated with puerperality were minority at $2.8 \%$ (108 cases). Table 1 summarizes the distribution of cases according to ICD 10 .

Table I Distribution of cases of psychotic disorders according to ICD I0

\begin{tabular}{lll}
\hline Diagnoses according to ICD I0 & $\begin{array}{l}\text { Absolute } \\
\text { frequencies(N) }\end{array}$ & $\begin{array}{l}\text { Relative } \\
\text { frequencies (\%) }\end{array}$ \\
\hline Schizophrenic disorders & 1291 & 34,3 \\
$\begin{array}{l}\text { Acute delusional disorders } \\
\begin{array}{l}\text { Mental disorders related to } \\
\text { psychoactive substances }\end{array}\end{array}$ & 1207 & 32,1 \\
$\begin{array}{l}\text { Chronic hallucinatory psychotic } \\
\text { disorders }\end{array}$ & 336 & 15,0 \\
$\begin{array}{l}\text { Chronic Non-dissociative psychotic } \\
\text { disorders }\end{array}$ & 255 & 8,9 \\
$\begin{array}{l}\text { Mental disorders associated with } \\
\text { puerperality }\end{array}$ & 108 & 6,9 \\
\begin{tabular}{l} 
Total \\
\hline
\end{tabular} & 3763 & 2,8 \\
\hline
\end{tabular}

\section{Socio-demographic characteristics}

The mean age of hospitalized patients was 34.3years with a standard deviation of 20.3years. Men were in the majority with a sex ratio $(\mathrm{M} / \mathrm{F})$ of 1.5 . The unmarried, the childless, the uneducated were more frequent. Most of the patients were orphans. Table 2 summarizes the socio-demographic characteristics of the patients.

\section{Professional characteristics}

The majority of patients reported having a vocational qualification. The $93.2 \%$ had a job in the private sector. The $36.3 \%$ had a domestic job. It had $1.4 \%$ of learners and $2.9 \%$ of unemployed. Table 2 summarizes the occupational characteristics of the patients. Multivariable analysis has shown that age, educational level, orphan status, family support, geographic origin are risk factors for psychosis. Table 3 gives the results of the multivariate analysis made by a simple logistic regression.

Table 2 Distribution of hospitalized patients by socio demographic and occupational characteristics

\begin{tabular}{ll}
\hline Socio-demographic characteristics & $\mathbf{N}(\%)$ Or $\boldsymbol{\mu ( \pm E ~ ) ~}$ \\
\hline Age(year) & $34.3( \pm 20.3)$ \\
Gender : male & $4435(61.2)$ \\
Marital status & \\
Single & $4112(57.1)$ \\
Married & $2453(34.1)$ \\
Divorced & $373(5.2)$ \\
Widower & $259(3.6)$ \\
Patient's number of children & \\
No Child & $6671(91.8)$ \\
between I to 6 children & $503(6.9)$ \\
More than 6 children & $95(1.3)$ \\
Religion & \\
Muslim & $6751(92.9)$ \\
Catholic & $516(7.1)$ \\
\hline
\end{tabular}


Table Continued..

\begin{tabular}{|c|c|}
\hline Socio-demographic characteristics & $\mathbf{N}(\%)$ Or $\mu( \pm E)$ \\
\hline \multicolumn{2}{|l|}{ Level of Study } \\
\hline University & $295(4.1)$ \\
\hline Secondary school & $1298(18.1)$ \\
\hline Primary & $1917(26.7)$ \\
\hline Quranic learned only & $1169(16.3)$ \\
\hline No school education & $2509(34.8)$ \\
\hline \multicolumn{2}{|l|}{ Geographic Origin } \\
\hline Urban & $2970(42.4)$ \\
\hline Rural & $4039(57.6)$ \\
\hline \multicolumn{2}{|l|}{ Marital Status of the Family of Origin } \\
\hline Polygamous & $4054(59.0)$ \\
\hline Monogamous & $2812(40.9)$ \\
\hline Divorced & $\mathrm{I}(0.0 \mathrm{I})$ \\
\hline \multicolumn{2}{|l|}{ Parents Experience } \\
\hline Parents in life & $3303(51.0)$ \\
\hline deceased Father & $1760(27.2)$ \\
\hline deceased Mother & $375(5.8)$ \\
\hline deceased Parents & $1038(16.0)$ \\
\hline Good family support(Yes) & $6698(97.5)$ \\
\hline Caractéristiques professional's & $n(\%)$ or $\mu( \pm \varepsilon)$ \\
\hline Existence of professional qualification(yes) & $4690(68.3)$ \\
\hline \multicolumn{2}{|l|}{ Employment Sector } \\
\hline Public & $292(6.8)$ \\
\hline Private/ liberal & $3995(93.2)$ \\
\hline \multicolumn{2}{|l|}{ Type of Occupation } \\
\hline House work & $1555(36.3)$ \\
\hline Farmer/ Breeder & $985(23.0)$ \\
\hline Trader & $494(11.5)$ \\
\hline Worker/ artisan & $459(10.7)$ \\
\hline Teacher & $179(4.2)$ \\
\hline Esthetician/ tailor & $169(3.9)$ \\
\hline Driver & $162(3.8)$ \\
\hline Fisher & $62(1.4)$ \\
\hline Artist & $56(1.3)$ \\
\hline Restaurant/hotel & $50(1.2)$ \\
\hline Administrative & $46(1.1)$ \\
\hline Security/ military & $36(0.8)$ \\
\hline Health worker & $16(0.4)$ \\
\hline Contractor & $15(0.3)$ \\
\hline Religious & $3(0.1)$ \\
\hline unemployment(yes) & $135(2.9)$ \\
\hline Learner status(student/ school boy(yes) & $99(1.4)$ \\
\hline Retired status(yes) & $249(10)$ \\
\hline
\end{tabular}


Table 3 Psychotic risk factors by logistic regression

\begin{tabular}{|c|c|c|c|}
\hline & \multicolumn{3}{|c|}{ Psychotic } \\
\hline & $\mathbf{P}$ & ODD Ratio adjusted [95\% IC] & ODD Ratio gross [95\% IC] \\
\hline \multicolumn{4}{|l|}{ Age } \\
\hline$[1 \mathrm{yr}-15 y \mathrm{rs}]$ & ref & - & - \\
\hline [16 yrs-40yrs] & $2.10^{-16}$ & $6.5[5.0-8,5]$ & $8.2[6.6-10.3]$ \\
\hline More than $40 y r s$ & $2.2 .10^{-16}$ & $5.69[4.1-7.7]$ & $5.2[4.1-6.6]$ \\
\hline \multicolumn{4}{|c|}{ Patient marital status } \\
\hline Single & ref & - & - \\
\hline Married & $1.3 .10^{-5}$ & $0.7[0.6-0.8]$ & $0.8[0.7-0.9]$ \\
\hline Divorced & 0.2 & - & $1.3[1.04-1.6]$ \\
\hline Widow & 7.2.1 $10^{-7}$ & $0.4[0.2-0.5]$ & $0.3[0.2-0.5]$ \\
\hline \multicolumn{4}{|c|}{ Level of education } \\
\hline No education & ref & - & - \\
\hline University & 0.001 & $1.6[1.3-2.3]$ & $1.8[1.4-2.3]$ \\
\hline Secondary & $1.5 .10^{-11}$ & $1.9[1.5-2.3]$ & $2.0[1.7-2.3]$ \\
\hline Primairy & 4.8.10-8 & $1.5[1.3-1.8]$ & $1.6[1.4-1.9]$ \\
\hline Coranic teaching & 0.08 & - & $1.4[1.2-1.6]$ \\
\hline \multicolumn{4}{|c|}{ Childhood environment } \\
\hline Urban & ref & - & - \\
\hline Rural & 0.08 & - & $0.8[0.7-0.8]$ \\
\hline \multicolumn{4}{|l|}{ Parental status } \\
\hline Parents in life & ref & - & - \\
\hline Deceased father & 0.0001 & $1.3[1.1-1.5]$ & $0.8[0.7-0.9]$ \\
\hline Deceased mother & 0.006 & $1.4[1.1-1.9]$ & $1.5[1.2-1.9]$ \\
\hline Deceased Parents & 0.22 & - & $1.5[1.3-1.7]$ \\
\hline \multicolumn{4}{|c|}{ Good family support } \\
\hline No & ref & - & - \\
\hline Yes & $4.5 \cdot 10^{-12}$ & $0.2[0.1-0.3]$ & $0.2[0.1-0.2]$ \\
\hline \multicolumn{4}{|c|}{ Existence of one qualification } \\
\hline Yes & ref & - & - \\
\hline No & $4 \cdot 0.10^{-12}$ & $1.5[1.3-1.8]$ & $1.3[1.2-1.5]$ \\
\hline \multicolumn{4}{|l|}{ Learner status } \\
\hline No & ref & - & - \\
\hline Yes & 0.002 & $0.3[0.1-0.6]$ & $0.5[0.3-0.9]$ \\
\hline
\end{tabular}

\section{Discussion}

This retrospective study was confronted with missing values in the exploration of hospitalization records. Consultation activities were not explored because of the incompleteness of sociodemographic information and especially clinical diagnosis. But we had a statistically representative number of records to do the logistic regression. A psychosis is a mental disorder characterized by the loss of contact with reality, a disorganization of the personality, and the delirious transformation of experience. Psychoses are thus distinguished from neuroses, in which the patient retains the notion of the real, even if sometimes he does not understand the interpretation. In a neurosis, the subject retains a critical mind towards his illness. Chronic psychoses include chronic delusions, schizophrenia, paranoia, chronic hallucinatory psychosis (psychiatric hallucinations). Psychotic disorders, opening on a delusional experience, occur in several circumstances. ${ }^{6}$ Because of their physical, economic and social consequences, psychoses are very serious diseases. This study estimated the extent of these psychotic pathologies to be 3763 inpatients between November 2003 and April 2014 in this small 23bed mental health center. On average we found one case of psychotic hospitalization per day for more than 10years. The proportional 
morbidity of psychoses in hospitalization in this structure is $77.6 \%$. It is thus the leading cause of hospitalization, which is explained by its seriousness. The Kirkbride meta-analysis showed a lower prevalence of psychotic disorders $(4 \%)$ but was in the general population. ${ }^{7}$ Schizophrenic disorders accounted for $34.3 \%$ of cases of psychosis. The longer period of study could be the limitation of this study. A rural geographic origin protected against psychosis $(\mathrm{OR}=0.8$ $\mathrm{IC}=[0.7-0.88])$. Urbanization would be a factor in aggravating or decompensating psychosis with a very high risk. ${ }^{8}$ Lifestyle and education different from the city to the countryside. In Senegal, rural life is very communal with broad social support that differs from the urban organization that is becoming more and more nuclear. With the difficulties of life in the countryside, education is based on traditional, religious and resilience concept called in wolof "mougn". Exposure to psychosis is higher among people aged 16 to 40years. This result agrees with the age of schizophrenia. ${ }^{9}$ This age group represents a large part of the working population, hence the importance of the impact of psychiatric pathologies on the development of a country. The married couple are less exposed to psychosis $(\mathrm{OR}=0.7 \mathrm{IC}=[0.6$ - 0.8] or psychosis which is a chronic disease, usually days social does not allow the patient to be able to marry. The orphan is exposed to psychosis through the lack of a solid social fabric and a parental framework in the psychological development of the person, in medical assistance and therapeutic follow-up. This lack of follow-up of certain orphans may trigger predisposing factors or the complication of a psychotic state that may associate it with mood disorders. This result agrees with the usefulness of family support in the medical follow-up of the psychotic $(\mathrm{OR}=0.2 \mathrm{IC}=[0.1-0.3])$. Therapists often involve the family in the follow of the sick at home. They understood the importance of the family in the follow-up of psychotics. ${ }^{10,11}$ To facilitate the involvement of families, the accessibility of mental health services should be improved through decentralization of mental health care to different levels of the health pyramid by identifying the appropriate service packages. ${ }^{12}$ The risk of psychosis is higher in patients without qualifications $(\mathrm{OR}=1.5 \mathrm{IC}=[1.3-1.8])$. Student status would protect against psychosis with $\mathrm{OR}=0.3 \mathrm{IC}=[0.1-0.6]$. This result would also be related to the mental handicap of the disease, which means that patients do not have the opportunity to follow the normal educational cycle, which leads to an early termination of studies and a lack of qualification. ${ }^{13}$

\section{Conclusion}

Fatick's Dalal Xel Mental Health Center is a small, 23-bed facility that receives an average of 700 patients per year. It hosts all psychiatric pathologies, neurological pathologies and even medical emergencies. The risk factors for psychotic disorders are age, marital status, orphan status and inadequate family support.

It is important to involve the family in the follow-up of patients and in the implementation of mental health policies. For better prevention of psychotic disorders, a good policy should be put in place to raise awareness about risk factors and decentralization of mental health care.

\section{Acknowledgements}

None.

\section{Conflict of interest}

Author declares that there is no conflict of interest.

\section{References}

1. The global economic burden of non-communicable diseases. World Economic Forum \& Harvard School of Public Health, Geneva: World Economic Forum; 2011.

2. Cohidon C. Prevalence of mental health disorders and consequences on occupational activity in France in the Mental health in the general population: images and realities survey. Institute for Health Surveillance. France; 2007.

3. Tine Benoit. Addiction: Sociological Study of a Form of Deviance in Senegal. 2008.

4. Collet D. Modeling binary data. London: Chapman and Hall/CRC; 2003. 387p.

5. Hosmer DW, Lemeshow S. Applied logistic regression. New York: John Wiley; 1989. 307 p.

6. Besançon G. Psychoses. Manual of Psychopathology. Dunod; 1993.

7. Kirkbride JB, Errazuriz A, Croudace TJ, et al. Systematic Review of the Incidence and Prevalence of Schizophrenia and Other Psychoses in England. Department of Health Policy Research Program, London; 2012.

8. Harrison G, Fouskakis D, Rasmussen F, et al. An association between psychotic disorder and urban place of birth is not mediated by obstetric complications or childhood. Psychol Med. 2003;33(4):723-731.

9. Jones PB. Schizophrenia \& Psychotic Disorders: Current epidemiological highlights. CEPiP. 2011;3(1):6

10. Friesen B, Katz-Leavy J, Nicholson J. Supporting Parents With Mental Health Needs in Systems of Care. Technical Assistance Partnership for Child and Family Mental Health. Washington, DC; 2011.

11. Leclerc L. Being a caregiver close to a person living with a mental health disorder in a high-speed society. The partner. Quebec; 2012;20(4):6.

12. Diop B, Collignon R, Gueye M. "Presentation of the collaborative study of the O.M.S. On strategies for extending mental health care". Psychopath XII. 1976;2:173-188

13. Perälä J, Suvisaari J, Saarni SI, et al. Lifetime prevalence of psychotic and bipolar disorders in a general population. Arch Gen Psychiatry. 2007;64(1):19-28. 